\section{ON THE OCCURRENCE OF WIDMANN-} STATTEN'S FIGURES IN STEEL CASTINGS.

SOME little time ago, during his inspection of the $S$ metallurgical laboratories at the University College of Sheffield, Sir Norman Lockyer exhibited considerable interest in the fact then communicated to him that almost invariably small steel castings exhibited in the first stage of their manufacture the Widmannstätten figures, provided that the carbon was near the semi-saturation point of steel, namely, 0.45 per cent. The authors communicated the following brief note in the hope that it would be interesting to mineralogists and astronomers.

For many years an exhaustive research into the properties of steel castings has been proceeding at the Sheffield College. This research necessarily involves a close investigation of the influence of mass; hence the weight of the experimental castings varies from about $28 \mathrm{lb}$. to 2 tons. In such heavy castings as those last named the Widmannstätten figures are seldom found, the slow cooling of the mass exerting an influence similar to that of annealing, an operation which, as will presently be seen, causes a change in structure so profound as almost always to destroy the figures. The authors therefore selected for purposes of demonstration research casting No. 541, weighing about $30 \mathrm{lb}$. The mean analysis of drillings from this metal, taken from a portion of the casting $1 \frac{3}{8}$ inches in diameter, registered the following figures:-

\begin{tabular}{|c|c|c|c|c|c|}
\hline Carbonn & & $\ldots$ & $\cdots$ & $\ldots$ & $\begin{array}{c}\text { Per cent. } \\
0.39\end{array}$ \\
\hline Silicon & $\ldots$ & $\ldots$ & $\ldots$ & $\ldots$ & 0.08 \\
\hline Manganese & $\ldots$ & $\ldots$ & .. & $\ldots$ & 0.03 \\
\hline Sulphur & $\ldots$ & $\cdots$ & $\ldots$ & $\ldots$ & 0.03 \\
\hline Phosphorus & $\ldots$ & $\ldots$ & $\ldots$ & $\ldots$ & 0.02 \\
\hline Aluminium & $\ldots$ & $\ldots$ & $\ldots$ & $\ldots$ & 0.03 \\
\hline Iron by diffe & rence & $\ldots$ & $\ldots$ & $\ldots$ & $99 \cdot 42$ \\
\hline
\end{tabular}

The structure of the metal as cast is shown in the upper half-section of Fig. I. As usual, it exhibits two

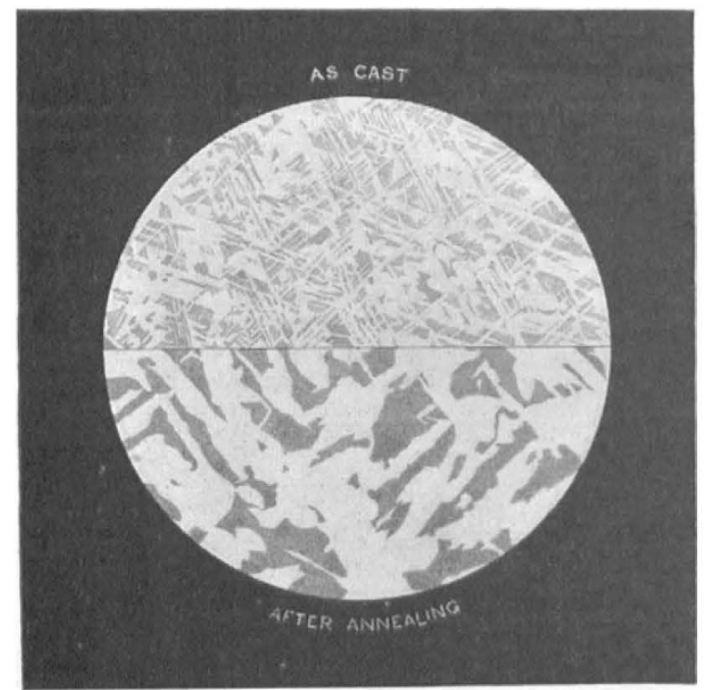

FIG. I. - Research casting $\varsigma_{4} x$. Reduced from micrograph. Magnified 22 diameters.

constituents, the magnification being too low to reveal its third and fourth constituents, namely, the sulphides of manganese and iron also present in minute quantities. The dark etching constituent is pearlite $\left(2 \mathrm{IFe}+\mathrm{Fe}_{3} \mathrm{C}\right)$, its colour being due to the liberation during etching of an automatic stain composed of that dark, carbonaceous colouring matter upon which the well-known carbon colour test depends. The pale con- stituent is, of course, ferrite, in this case nearly pure iron, and has obviously assumed that crystalline structure characteristic of the Widmannstätten figures.

The lower half-section of Fig. I delineates the structure of the metal after the operation of annealing. The two stages of annealing were carried out as follows:-first, the steel, protected so far as possible
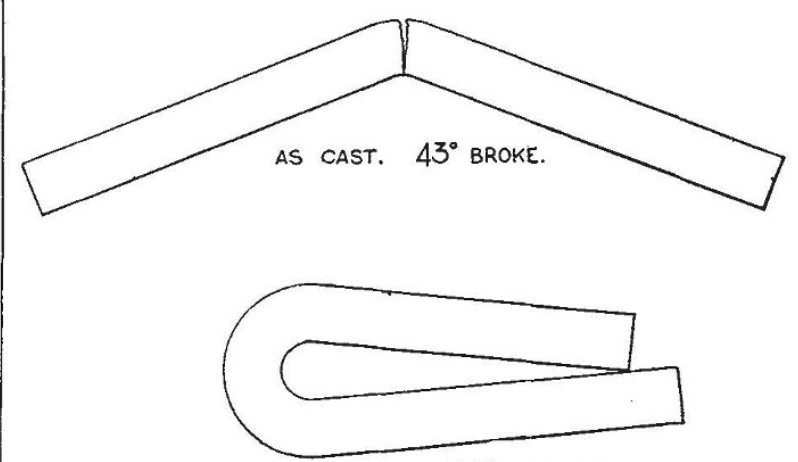

AFTER ANNEALING, $180^{\circ}$ UNBROKEN.

F1G. 2. -Dimensions of test-pieces :- $-10^{\prime \prime} \times \frac{31}{4}$ diam. ; bending radius, $\frac{3}{8}{ }^{\prime \prime}$.

from the air, was maintained for about seventy hours at a temperature of about $950^{\circ} \mathrm{C}$.; secondly, it was allowed to cool very slowly, occupying, perhaps, another seventy hours in falling to a temperature at which it could be comfortably handled. The result was a total re-arrangement of the pattern presented by the ferrite and pearlite, and a consequent elimination of the figures. This change in structure was accompanied by a profound change also in the mechanical properties of the steel.

Fig. 2 reproduces, before and after annealing, bending tests made on bars 10 inches long and $\frac{3}{4}$ inch in diameter. The metal as cast snapped sharply after bending through an angle of $43^{\circ}$ over a radius of $\frac{3}{8}$ inch. The annealed steel bent through an angle of $180^{\circ}$ without exhibiting any signs of fracture. At the request of Prof. Lewis, of Cambridge University, the authors have submitted to him duplicate sections of the steels figured in this paper. Prof. Lewis considers that an interesting point raised is as to whether the occurrence of the Widmannstätten figures in pieces of metallic iron dug out of the earth necessarily proves them to be of meteoric origin.

The authors have to thank their colleague Mr. J. H. Wreaks, demonstrator of metallography at the Sheffield College, for his patient and precise reproduction of the structures figured in this note.

A. McWilliam.

\section{FORESTRY IN THE UNITED STATES.}

$A$ MONG the professional papers of the United A States Geological Survey we have already noticed the first six reports dealing with the various forest reserves in the States of Oregon, Washington, and California. The two latest reports, Nos. 7 and 8, now to hand, deal with the forest conditions in the San Francisco Mountains Forest Reserve and the Black Mesa Forest Reserve in the State of Arizona. The former report is by John B. Leiberg, Theodore F. Rickson, and Arthur Dodwell, with an introduction by F. G. Plummer; while the latter report was prepared by F. G. Plummer from notes by Theodore F. Rickson and Arthur Dodwell. Both forest reserves were first created by proclamation of President M'Kinley, dated August 17 , I898. The region in which the San Francisco Mountains Forest Reserve

NO. I 828 , VOL. 7 I] 
is situated forms a kind of plateau, traversed by numerous deep canons and dotted by several hundred

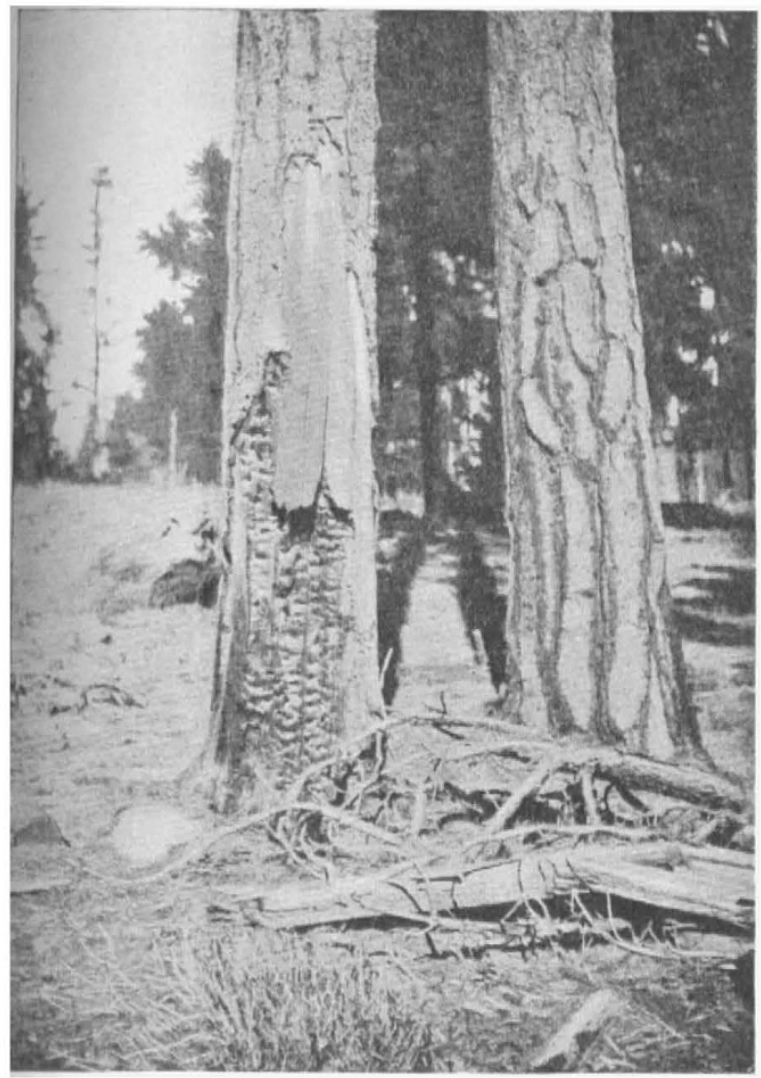

Fig. 1.-Fire Scars on Yellow Pine.

volcanic cones, which vary in height from roo feet to Iooo feet. The soil is various, but gravelly loam is the prevailing type. On the slopes of the volcanic cones and ridges in their neighbourhood scoriaceous soils prevail. The water-retaining capacity of the latter class of soil is not very great. The loamy soils are best adapted for forest growth. As regards drainage, the visible run of permanent surface flow is small. Most of the precipitation sinks either within the reserve or in the desert or semi-desert tracks which border it.

Electric storms do considerable damage to the standing crop in the reserves, and it is estimated that in some places as many as 5 per cent. of the trees have been struck and killed by lightning. There are twelve coniferous species in the reserve, but the yellow pine predominates, producing more than 99 per cent. of the merchantable timber, and forming 90 per cent. of the total forest. About the same number of broad-leaved species occur, but a complete list of them is not available. All over the reserve the stands of yellow pine do not carry an average crop of more than 40 per cent. of the timber they are capable of producing.

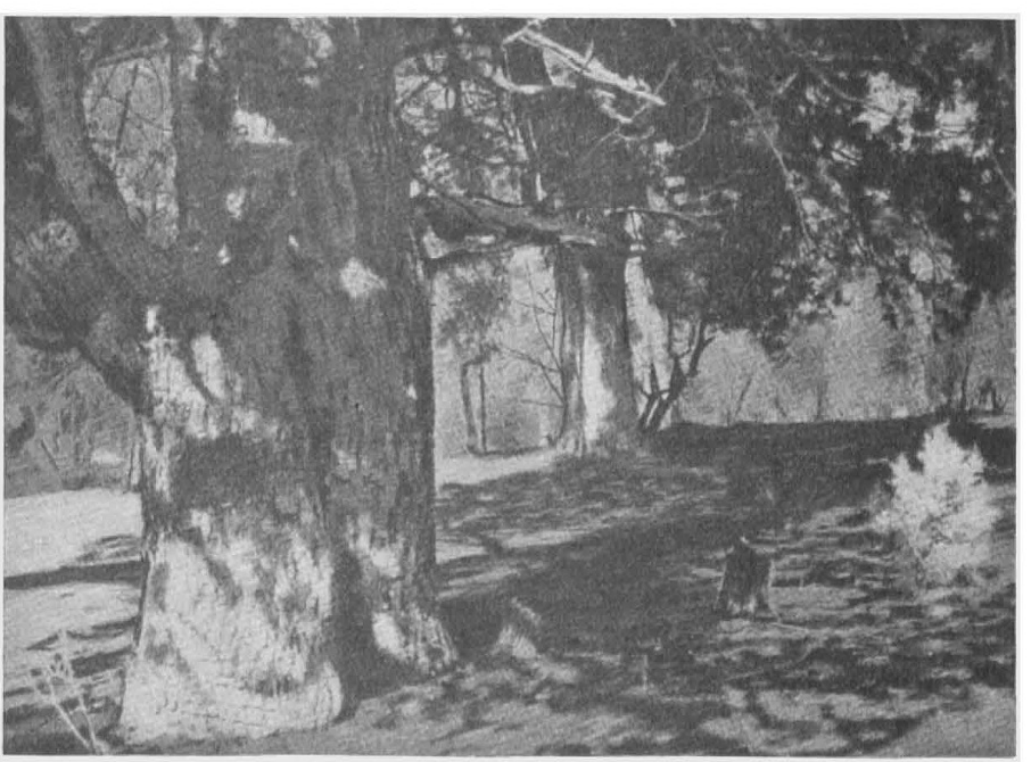

Fig. 2.-Large Growth of Alligator Juniper.

A very striking feature of the report is the decrease in the water supply due to successive seasons of drought, which have practically destroyed the value
This unsatisfactory condition is attributable to the numerous fires which have occurred in this region within the last 200 years. In addition to the destruction caused by fire, careless cutting and grazing have done much damage in the reserve.

The reproductive capacity of the yellow pine in the reserve is extremely small-there being a great deficit in seedling and sapling growth. There has apparently been a complete cessation of reproduction over large areas during the past twenty or twenty-five years. This low reproductive capacity is attributed to various causes-some depending on the operation of natural agencies, others on human intervention. The grazing value of the reserve was at one time very great. As the gramineous flora of the region is a rich one, there was formerly a luxuriant growth of grass, but owing to the persistent and excessive pasturing, especially by sheep, the turf-forming grasses were reduced in size and vegetative activity, which led to various changes in the character of the subsequent vegetation. What was formerly pasture land is now covered by exuberant growths of various low desert shrubs and herbaceous Composita, particularly species of sunflowers.

The agricultural value of the region is not great, there being only some 2500 acres under the plough, and these occur in the now dry beds of what were formerly Stone-man and Mormon lakes, or at the foot of ridges where local areas of secpage exist. The crops consist of oats, wheat, and potatoes. There is no fruit culture in this region. This reserve, like the others, is subdivided into townships and ranges, the detailed descriptions of which are included in the report. At the end we have a very useful summary, showing in tabular form a classification of lands in the reserve by townships. The maps and photographic illustrations are of the same high standard as those which accompany the other reports of this series.

The Black Mesa Forest Reserve comprises an area

\begin{tabular}{lcc|cccc} 
& \multicolumn{3}{c}{ Square miles. } & & \multicolumn{3}{c}{ Square mil } \\
Timbered area & $\ldots$ & $\mathbf{2 2 4 8} 5$ & Burned area & $\ldots$ & $\ldots$ & $5 \cdot 5$ \\
Woodland $\ldots$ & $\ldots$ & 391 & Logged area & $\ldots$ & $\ldots$ & $1 \cdot 0$ \\
Timberless area & $\ldots$ & 140 & & & &
\end{tabular}
of 2786 square miles, made up as follows:- 
of the grazing and agricultural areas in the reserve. Three years ago the wheat crop yielded 5000 bushels. The following year it fell to 2500 bushels, and last season the yield was only 800 bushels. A cattle ranche in the range, which used to graze more than 100,000 head, will now support not more than 9000 head. As a remedy it is suggested to adopt stringent rules, regulating the number of stock and the areas on which they shall be grazed on each permit. Very little lumbering has been carried out within the reserve, which is apparently due to the difficulties and expense of transport. The timber species, coniferous and broad-leaved, number fifteen, the yellow pine being the principal timber tree. It is distributed uniformly throughout the extent of the reserve. In some ranges it forms a pure forest. Its average height is $125 \mathrm{feet}$, with 24 feet of clear trunk with a diameter of 18 inches at breast height. It varies in age from 125 to ${ }_{50}$ years.

The Engelmann's spruce occupies the moister areas above an altitude of 9000 feet. It averages 70 feet in height and Io inches in diameter. Its age varies from 50 to 75 years. Its growth is extremely rapid, but the tree is usually clothed with branches to the ground. A variety of the Engelmann's spruce, Picea engelmannii, var. Franciscana, known as the Arizona spruce, gives much better results, averaging roo feet in height with 20 feet of clear trunk and a diameter of 18 inches. Red fir, white fir, western white pine, alligator juniper, and Arizona cypress also occur within the area. The deciduous trees are confined to the borders of streams and marshy areas. The reproductive capacity of the various species is exceptionally good, especially where the young growth is afforded shelter by the larger trees. The underbrush throughout the areas in which the yellow pine predominates is very small, and consequently this region has not suffered much injury from forest fires. The report also embodies detailed descriptions of the various subdivisions of the range, together with carefully prepared maps and beautiful photographic plates. Of the latter we have reproduced two as an example of the interesting way in which these papers are illustrated.

\section{TECHNICAL EDUCATION IN LONDON. ${ }^{3}$}

$T$ HE last report of the Technical Education Board of the London County Council, dealing with the year 1903-4, directs special attention to the progress made in the provision of technical, secondary, and higher education in London during the past eleven years. Under the recent Education Act (London), I903, the administration of the whole of the education of London passed into the hands of the new Education Committee, and the Technical Education Board ceased to exist. The present report is consequently opportune, and serves to record the great services which have been rendered to education in London by the late Board.

The most striking features of the report are the evidences provided of the increase and rapid development of polytechnic institutions, the establishment and success of London County Council schools and technical institutes, and the improvement in the equip. ment and staffing of secondary schools. The extent of the advances made can be estimated satisfactorily by comparing the number of educational institutions providing good scientific and technical education at the time of the supersession of the Technical Board with the number in existence in 1893 , when Mr. Llewellyn Smith reported on the provision made for technical

1 "Annual Report of the Technical Education Board of the London County Council, 1903-1904." (Westminster: P. S. King and Son, 1904.) Price 2s. 6 d.

$$
\text { No. I } 828 \text {, vOL. } 7 \text { I] }
$$

instruction at that time. To take the case of the laboratory accommodation for the teaching of chemistry. In 1893 there appear to have been about fourteen chemical laboratories in London open in the evening for instruction; since that time well equipped departments for teaching practical chemistry have been opened in eleven new polytechnic institutions. The total volume of instruction in evening classes in chemistry in 1893 was only about 38 , 000 student-hours. per session, and in polytechnics under 15,000 studenthours. In 1893, after omitting the attendances of students who did not attend for more than twenty hours during the session, the amount of time devoted to evening work in theoretical and practical chemistry amounted to 64,554 student-hours in the polytechnics. alone.

The result obtained by comparing the advance made in the teaching of electricity and electrical technology is just as striking as in the case of chemistry. In 1893 there were five electrical laboratories open for evening instruction, while in 1903 there were twenty-three institutions giving evening instruction in electricity or electrical technology, or both. In practical electrical engineering there were only four centres in 1893 available for evening instruction, and only one applied for aid from the Board, and at this institution there were thirty-eight students. During the session 1902-3 there were, in polytechnics aided by the Board, a large and increasing number of students for electrical engineering, and the volume of instruction, omitting students. who attended for less than twenty hours during the session, amounted to 43,909 student-hours. In addition to these, a large number attended classes in electricity and magnetism in the physics departments of the institutions. The volume of instruction here reached 32,872 student-hours.

Ten years ago there was scarcely any provision in London for pure technological teaching. From the list of evening classes for 1903 it appears that technological instruction is now available in a great variety of subjects, of which the most important are:-bricklaying and brick-cutting in twelve institutions, cabinetmaking in nine, carpentry and joinery in twenty, furniture design in nine, masonry in nine, metal-plate work in eight, painting and decorating in twelve, photoprocess work in four, plastering in nine, plumbing in fifteen, printing in four, smithing in six, tailors' cutting in seven, and upholstery in six. This rapid increase in the number of polytechnics and technical institutes in which adequate provision is made for practical instruction in trade subjects has had a remarkable effect in producing an interest in the scientific principles underlying the various trades concerned. As an example, the report quotes the case of the Northampton Institute in Clerkenwell, in which district there is a very large number of special trades. In order ${ }^{+} \mathrm{s}$ meet the demands of the neighbourhood, classes were started in subjects in which no organised technical instruction had previously been given in London. Some of these have been remarkably successful, and in several cases it has been found necessary to increase the number of evenings of instruction in order to provide for the large number of students in attendance.

There has been also, says the report, a natural tendency during the past few years for sporadic classes in trade subjects to disappear in consequence of the increasing popularity of the polytechnics and larger technical institutes, in which are found thoroughly well equipped laboratories and workshops. The number of distinct trades in which practical instruction is provided, and also the number of centres where such courses of instruction can be obtained, have more than doubled during the past nine years, 